\title{
Time-frequency analysis in pick cutting coal seam with small fault
}

\author{
Chenxu Luo ${ }^{1, a}$, Shuangxi JING ${ }^{1, b}$,Xiaoyu YANG ${ }^{1, c}$, Jinle YUAN ${ }^{1, d}$, and \\ Changlong $\mathrm{Du}^{2, \mathrm{e}}$ \\ ${ }^{1}$ School of Mechanical and Power Engineering, Henan Polytechnic University, Jiaozuo454000, \\ China \\ ${ }^{2}$ School of Mechanical and Electrical Engineering, China University of Mining and Technology, \\ Xuzhou221116,China \\ acumtlchx@hpu.edu.cn, \\ bjsx@hpu.edu.cn, '925826120@qq.com, ${ }^{\mathrm{d}} 403192862 @ q q . c o m,{ }^{\mathrm{e}} \mathrm{dcl} @$ cumt.edu.cn
}

Keywords: shearer drum; small fault; cutting experiments; time-domain analysis; frequency-domain analysis

\begin{abstract}
Based on the study of cutting theory of shearer pick-shaped cutter used in thin seams, cutting tests under different fault conditions were done by using pick on the Cutting Test Bed of the Coal and Rock. The results show that: picking Cutting Torque in the coal seam and small fault interface increases with the increase compressive strength difference between the coal seam and small fault. Meanwhile, the mean increments of the cutting torque did not change exponentially, when the thickness of full fault is twice the thickness of top fault or bottom fault in the cutting tests. Through time-domain analysis and frequency-domain analysis of cutting load, it can be seen that probability density curves of pick torque obeys normal distribution in cutting coal seams and small fault. The drum speed affects load fluctuations a lot different forms of coal and rock has some impact on the load fluctuation.
\end{abstract}

\section{Introduction}

With the continuous development of the coal industry, the level of coal science and technology improves continuously. Cutting performance research of drum pick is the theoretical basis of the shearer drum design, it affects specific energy of cutting, cutting efficiency, the amount of dust, and stability and reliability of the shearer drum directly. And domestic and foreign scholars have conducted a lot of tests on cutting performance research of drum pick, such as Xia Yimin, etc. [1-2] Simulation analysis method is used to study characteristics of load on the cutter and load distribution, and it pointed out that the maximum load pick obey normal distribution, which provided the theoretical guidance for the study of stress distribution of cutter. Chang Shou-chu[3-4] analyzed the optimization principle for the drum cutter arrangement, and described the optimized arrangement of checkerboard pick, which as a result laid the foundation for the drum cutter optimization arrangement. Mazurkiewicz[5-7] analyzed the relationship between the blade wrap angle and its cutting effect, and predict the formula of cutting force using the linear regression methods .Du et al. [8] , based on the establishment of the new relationship between the cutter and its cutting force, purposed to minimize the fluctuation coefficient, calculated the fluctuation coefficient of different cut pick arranged in the drum, which provided the theoretical basis for drum choose. Hu Ying Xi et al. [9] theoretically analyzed the relationship between the drum cut pick arrangement as well as the drum speed and traction speed, conducted the pulling speed of the drum at different speeds, different pick arrangement. Liu Songyong et al. [10-11], starting from the drum movement and structural parameters, analyzed the relationship between various parameters and drum cutting efficiency, cutting specific energy consumption, lump coal rate, the vibration characteristics of the coal loading effect, and provided a theoretical basis for the drum design. Aim to get more consistent with the actual condition, this paper made several experiment on a coal cutting test bed, studied on the nature of the coal and rock parameters, structural parameters and motion parameters, which may be related to the cutter drum cutting with small fault seam performance, and analyzed the cutting 
load time domain and frequency domain, so as to provide a theoretical basis for the design of cutting performance optimum cutter drum.

\section{Experiment Study on Drum Cutting Coal Seam with Gangue and Small Fault}

Based on the similar theory, the similar ratio we deduced dimensional matrix and similarity criteria, combined with drum shearer cutting theory, we established a coal and rock cutting test system for pick drum cutting performance test. In order to meet with the actual condition in conformity with the drum shearer cutting coal and rock, cutting power of coal cutting test-bed is 15 $\mathrm{kw}$, drum speed range is $0 \sim 200 \mathrm{r} / \mathrm{min}$, the coal seam translational velocity is $0 \sim 10 \mathrm{~m} / \mathrm{min}$, translation range is $0 \sim 2.5 \mathrm{~m}$, the hydraulic cylinder speed is $0 \sim 2 \mathrm{~m} / \mathrm{min}$.

\section{1 fault cutting test on different compressive strength}

In this paper, compressive strength of the simulated seam $0.69 \mathrm{MPa}$, compressive strength of simulated small fault were 1.07MPa, 2.73MPa, 4.55MPa. The coal or rock cutting test systems is used to collect the test data, and cutting torque curve of cutting is simulated. For statistics, the test data of the cutting torque acquisition obtained results are shown in Table 1.

Table 1 Cutting torque statistics for small fault coal seam with different compressive strength

\begin{tabular}{ccccc}
\hline \multicolumn{2}{c}{ Compressive strength } & $0.69 \mathrm{MPa} / 1.07 \mathrm{MPa}$ & $0.69 \mathrm{MPa} / 2.73 \mathrm{MPa}$ & $0.69 \mathrm{MPa} / 4.55 \mathrm{MPa}$ \\
\hline \multirow{2}{*}{ Mean Cutting torque } & Coal & 178.36 & 179.36 & 173.91 \\
& Rock & 292.74 & 399.34 & 507.66 \\
\multirow{3}{*}{ Peak Cutting torque } & Coal & 207.91 & 206.48 & 229.03 \\
& Rock & 329.81 & 442.39 & 544.39 \\
\multirow{2}{*}{ Min Cutting torque } & Coal & 149.88 & 150.82 & 154.93 \\
& Rock & 263.14 & 352.75 & 465.68 \\
\hline
\end{tabular}

\subsection{Incomplete small faults cutting test}

The actual small fault of coal face are in many forms, in order reflect the actual working conditions ,and better simulate the shearer drum encountered various forms of small faults, this article is specially made three incomplete faults form for drum cutting test. Simulated coal compressive strength is $0.69 \mathrm{MPa}$, simulated small faults compressive strength is $2.73 \mathrm{MPa}$. Coal rock cutting test system was used for simulation cutting test. Test data was collected and analyzed. Then, statistical analysis results are shown in Table 2.

Table 2 Cutting torque statistics for uncompleted small fault coal seam

\begin{tabular}{|c|c|c|c|c|}
\hline \multicolumn{2}{|l|}{ Fault coal seam } & \multirow{2}{*}{$\begin{array}{c}\text { Tор } \\
176.89\end{array}$} & \multirow{2}{*}{\begin{tabular}{|c|} 
Bottom \\
174.01
\end{tabular}} & \multirow{2}{*}{$\begin{array}{c}\text { Full } \\
177.41\end{array}$} \\
\hline Мозn Cuttina toraue & Coal & & & \\
\hline Miedal Cutung torque & Rock & 267.26 & 243.65 & 310.83 \\
\hline \multirow{2}{*}{ Peak Cutting torque } & Coal & 202.31 & 203.75 & 203.05 \\
\hline & Rock & 309.39 & 272.91 & 346.19 \\
\hline \multirow{2}{*}{ Min Cutting torque } & Coal & 154.11 & 154.33 & 154.81 \\
\hline & Rock & 235.25 & 208.89 & 261.18 \\
\hline
\end{tabular}

\section{Loading Spectrum Analysis of Pick Cutting Torque}

\subsection{Time-Domain Analysis of Experiment Load}

This paper take further research based on cutting test measured data on this case. The probability density of the cutting torque curve is drawn. Distribution and probability density curve of the different cutting test cutting torque is shown in Figure1.The cutting torque distribution can be analyzed directly from the cutting torque of the probability density curve. And values of peak point reflect the size of the centralized point of torque. 


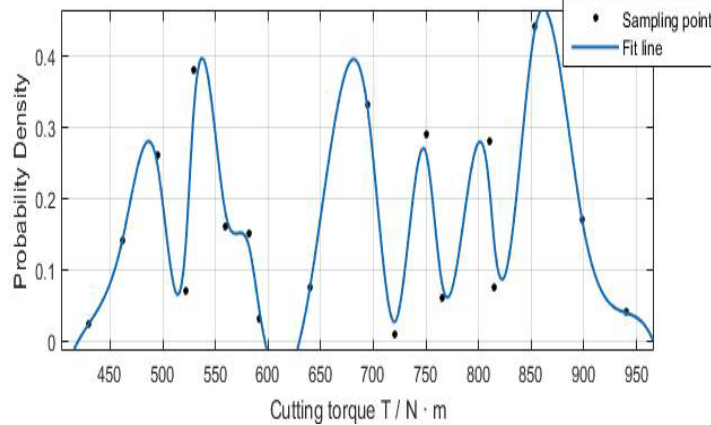

(a) 1.07Mpa fault seam

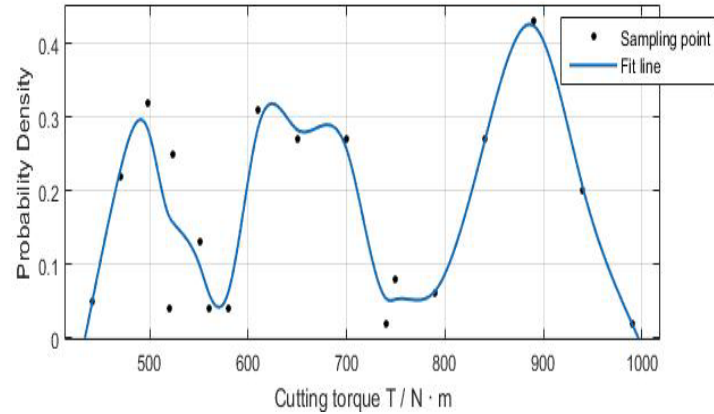

(c) $4.55 \mathrm{MPa}$ fault seam

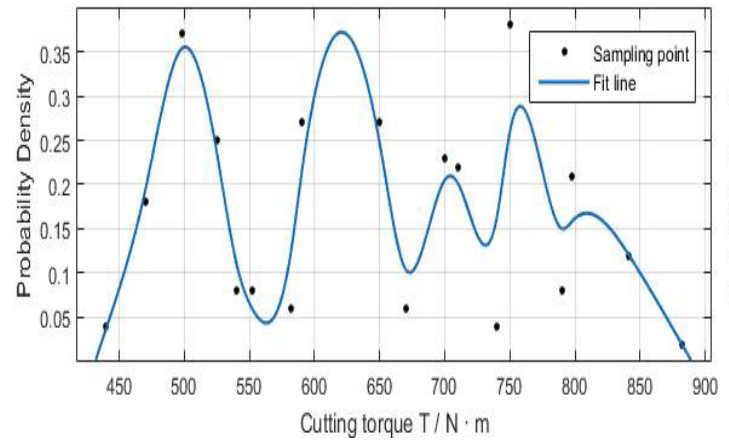

(e) bottom fault seam

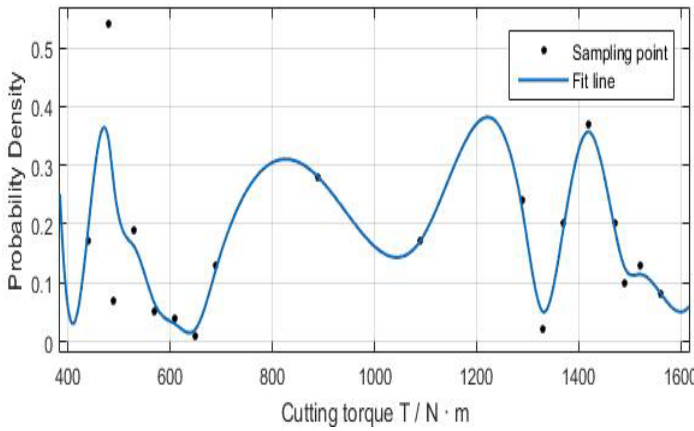

(b) 2.73MPa fault seam

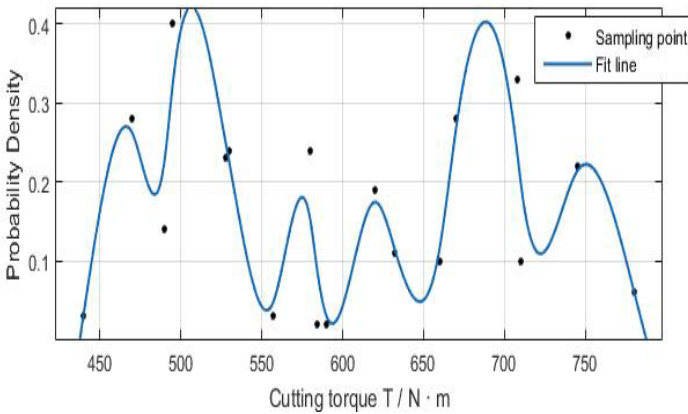

(d) top fault seam

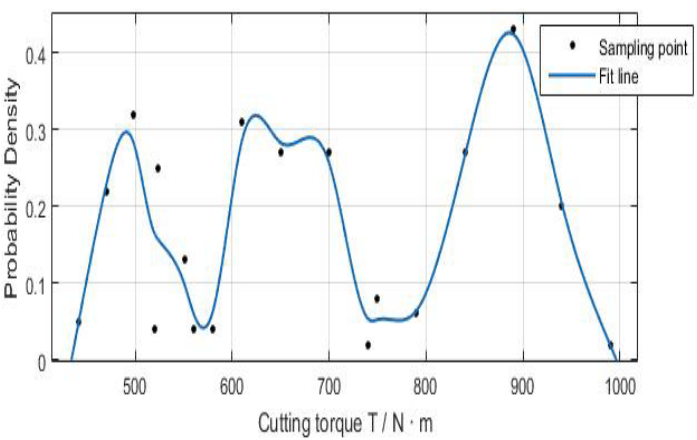

(f) full fault seam

Figure 1 Probability density curve of cutting torque with different small fault coal seams

As can be seen from Figure 1, with the increasing of the compressive strength of small faults, cut pick are formed from cutting the same compressive strength of the seam transition to small faults, the range of the variation of the torque continue to expand, and the average of the cutting torque is increasing, and the torque distribution in the transition has no regularity. When the pick cutting small fault, torque value of cutting the upper and lower fault is greater than the other two forms, and the cutting torque probability density curve is narrower concerned that the distribution is relatively concentrated. As the thickness of small faults is greater than the thickness of coal seam, the drum is cutting into the coal seam and then faults cutting the seam short time, so the mean of torque concentrated near the cut-off cut off layer.

\subsection{Frequency -Domain Analysis of Experiment Load}

When pick cutting homogeneous coal seam, the frequency is mainly concentrated in the $1.42 \sim 5.25 \mathrm{~Hz}$ and 21.24 to $26.17 \mathrm{~Hz}$, but trials drum is not only cutting homogeneous coal seam, but also cutting small faults and seam partings, so different form of coal wall be a certain impact on the frequency of the load fluctuations. Through test data collected when taking cutting experiment, cutting the load from the power spectrum can be obtained by programming the drum cutting under different experimental conditions, as shown in Figure 2. 


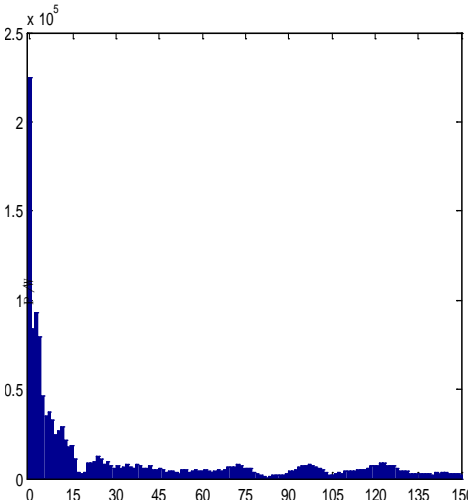

(a) 1.07MPafaultseam

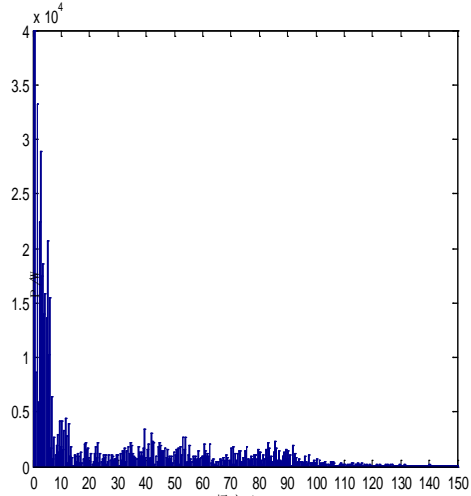

(d) top fault seam

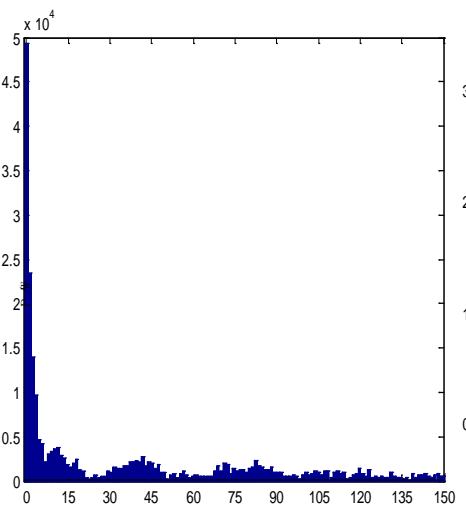

(b) 2.73MPafaultseam

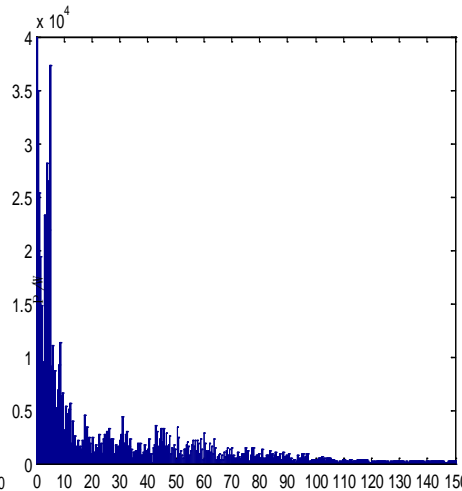

(e) bottom fault seam

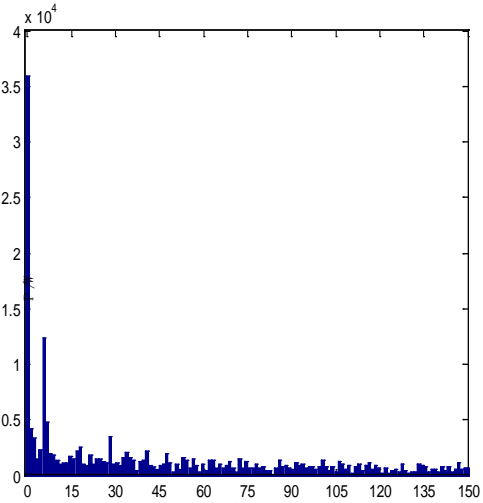

(c) 4.55MPafaultseam

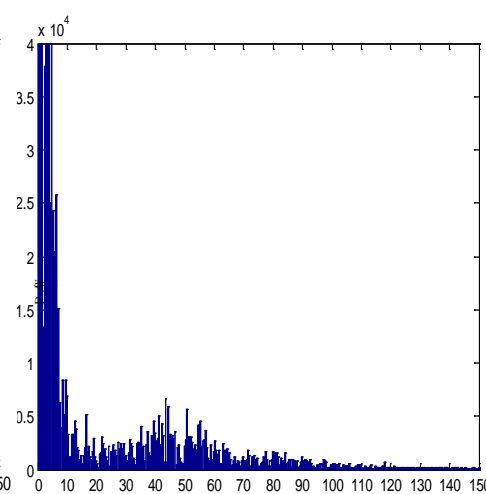

(f) full fault seam

Figure 2 Power spectrum of cutting load in different experiment conditions

According to the different experimental conditions, it can be seen from the picking Cutting Torque power spectrum that the frequency below $2 \mathrm{~Hz}$ following power spectral amplitude is larger, indicates that the speed of drum have a greater impact on load fluctuations. The vane head, pick and other factors on the speed of the drum have a smaller impact the load fluctuations. In addition, the different test high-frequency range, the relative amplitude of the power spectrum, cutting parting seam or small faults have a certain impact on the frequency of load fluctuations.

\section{Conclusion}

The analysis on drum cut coal seam test results with small faults shows that, with mean pick Cutting Torque difference between the coal seam and small faults interface increases, the compressive strength difference between them increase. Based on the time-domain analysis of the cutting load on the test, seen from the figure, the torque probability density curves when the drum cutting coal seams and small faults follow a normal distribution, while there is no obvious pattern for the torque probability density curve in the transition phase. Based on the theoretical analysis and frequency domain analysis of the pick cutting load, cutting torque power spectra is carried out under different experimental conditions, and indicate that different form of coal and rock will have some impact on the load fluctuation.

\section{Acknowledgements}

The authors are grateful for the funding of this work by the Henan province education department applied research project fund (16A460005) and Henan Polytechnic University doctor research project fund (660407/020)and China Postdoctoral Science Foundation Funded Project (Project No. 2016M592289).

\section{References}

[1] Liu S.Y., Luo C.X. Experimental modal research on the cutting system of EBZ-75 type 
boom-road header. Applied Mechanics and Materials, Vol. 278-280, 2013

[2] LIU Chun- sheng, LI De- gen. Influence of Random Load on Mechanical Properties of DoubleDrum Shearer [J]. Coal mine mechanical and electrical. 2012:4

[3] Yi-min XIA, Ying-yong BU, Bo-wen LUO, Xuan-yun QIN, Yue-hong DENG. Study on Fractal of Cobalt-rich Crusts Broken by Drum-type Mining Head. Mining and Metallurgical Engineering. 2005, 25: 9-11.

[4] C.X LUO, H.X. JIANG. Experimental Study on the Axial Force of Shearer Drum Cutting Coal and Rock [J].Recent Patents on Mechanical Engineering, 2015.Vol. 8, No.1

[5] C.X Luo, C.L Du, L.J Xu, K.H Zheng Fractal Distribution Studies of a Rotary Crushing Mechanism [J].Recent Patents on Mechanical Engineering, Vol.7, No.1, Jan 2014

[6] H. Tuncdemir, N. Bilgin, H. Copur, C. Balci. Control of rock cutting efficiency by muck size [J].International Journal of Rock Mechanics \& Mining Sciences, 2008, 45(2): 278-288.

[7] M. Entacher, G. Winter, T. Bumberger, K. Decker, I. Godor, R. Galler, Cutter force measurement on tunnel boring machines - System design, Tunnelling and Underground Space Technology, Vol 31, 2012,9: 97-106.

[8] B. Mishra. Analysis of cutting parameters and heat generation on bits of a continuous miner-using numerical and experimental approach. [D]. Thesis, West Virginia University, 2007.

[9] WANG Chun-hua, DING Ren-zheng, LI Gui-xuan, et.al. Simulation Experimental on the Deformation and Destruction Course of Coal Body under the Function of Pick Cutting [J]. Journal of China Coal Society, 2006, 31(1):121-124. (In Chinese)

[10] Liu S. Y., Luo C. X. Vibration experiment of shearer walking unit. Applied Mechanics and Materials, Vol. 268, Issue PART 1, 2013, p. 1257-1261.

[11] Rui ZENG, Changlong DU. Reasonable location parameters of pick and nozzle in combined cutting system [J]. Journal of central south university of technology, 2014, 21(3):1067-1076. 